\title{
Quantification and Evaluation of Soil Erosion in the Estuaries of Cameroon, Gulf of Guinea: Case of Nylon Area
}

\author{
Eric Flavien Mbiakouo-Djomo $\mathbb{D}^{1},{ }^{1}$ Ebénézer Njeugna $\mathbb{D O}^{1},{ }^{1}$ Denis Tcheukam-Toko, ${ }^{2}$ and \\ Didier Fokwa ${ }^{3}$ \\ ${ }^{1}$ Department of Mechanical and Electrical Engineering, ENSET, University of Douala, P.O. Box 1872, Douala, Cameroon \\ ${ }^{2}$ Department of Energy Engineering, IUT, University of N'gaoundere, P.O. Box 455, N'gaoundere, Cameroon \\ ${ }^{3}$ Department of Civil Engineering, ENSET, University of Douala, P.O. Box 1872, Douala, Cameroon
}

Correspondence should be addressed to Eric Flavien Mbiakouo-Djomo; mbiakouo_eric@yahoo.fr

Received 14 May 2017; Revised 20 November 2017; Accepted 22 November 2017; Published 11 February 2018

Academic Editor: Paul Voroney

Copyright (c) 2018 Eric Flavien Mbiakouo-Djomo et al. This is an open access article distributed under the Creative Commons Attribution License, which permits unrestricted use, distribution, and reproduction in any medium, provided the original work is properly cited.

\begin{abstract}
The area of Nylon represents a sensible and vulnerable environment where water erosion is the cause of many soil losses contributing to the production and movement of sediments from the upstream to the lowest depths. The high level of rainfall in this town, soil texture (sand-clay-silt), and the anarchic occupation of the area play a part in the important deterioration of the bare ground on the upstream of the catchment area. This causes with time an instability of structures and living places which can lead to their progressive disappearance. In order to assess the quantities of displaced sediments, the studies on the quantification of soil moved annually by water erosion are carried out. A direct method is used consisting in using a minisimulator of rain (NEME) in order to understand the phenomena involved and assess the quantity of sediments which can be moved. It helps in assessing erosion caused by the rain and extrapolating results over the catchment area of the chosen field of study. USLE relation has permit to make an extrapolation of the quantity of soil affected, and the result shows that the average potential of loss of soil is 153.57 t/ha/annum.
\end{abstract}

\section{Introduction}

Erosion is a modification of the natural topography due to rainfall and cohesion of soil particles and their transport. The phenomenon is particularly important in town, where the presence of building increases the volume of water flow. Soil erosion consists in displacing the particle from its natural position by destroying the bonding and its transport by water. The phenomenon increases with the hill slope and rainfall intensity as well as the global soil occupation.

In spite of numerous studies realised to understand and to give solutions to this phenomenon, behaviour of soil under climate changes and pollutants thrown in the nature are parameters that continue to make this phenomenon a subject of general interest for environmental sciences. Gulf of Guinea is an area where knowledge of soil texture and assessment of the impact of erosion phenomenon and its impact on structures and superstructures remain under exploration. In the early thirties, the first work on erosion concerned the farmland [1]. Through this research, Wischmeier [1] reached at "universal soil loss equation" due to rainfall erosion. He obtained an equation which was updated in 1978 and made easier to understand by users [2].

This equation has shown its limits, and some researchers have brought criticisms. Since then, many authors have tried to bring solutions to erosion phenomena through various methods. Prediction technics of erosion based on physical methods have emerged in the 70s. The development of remote sensing, geographical information systems and the use of radioisotope (caesium-137) have brought a considerable advancement in that domain. Notice that those methods developed are less precise or do not take into account interactions among different factors of erosion.

Structural characteristics of the surface of soil are then at the centre of water erosion phenomena. This is widely 


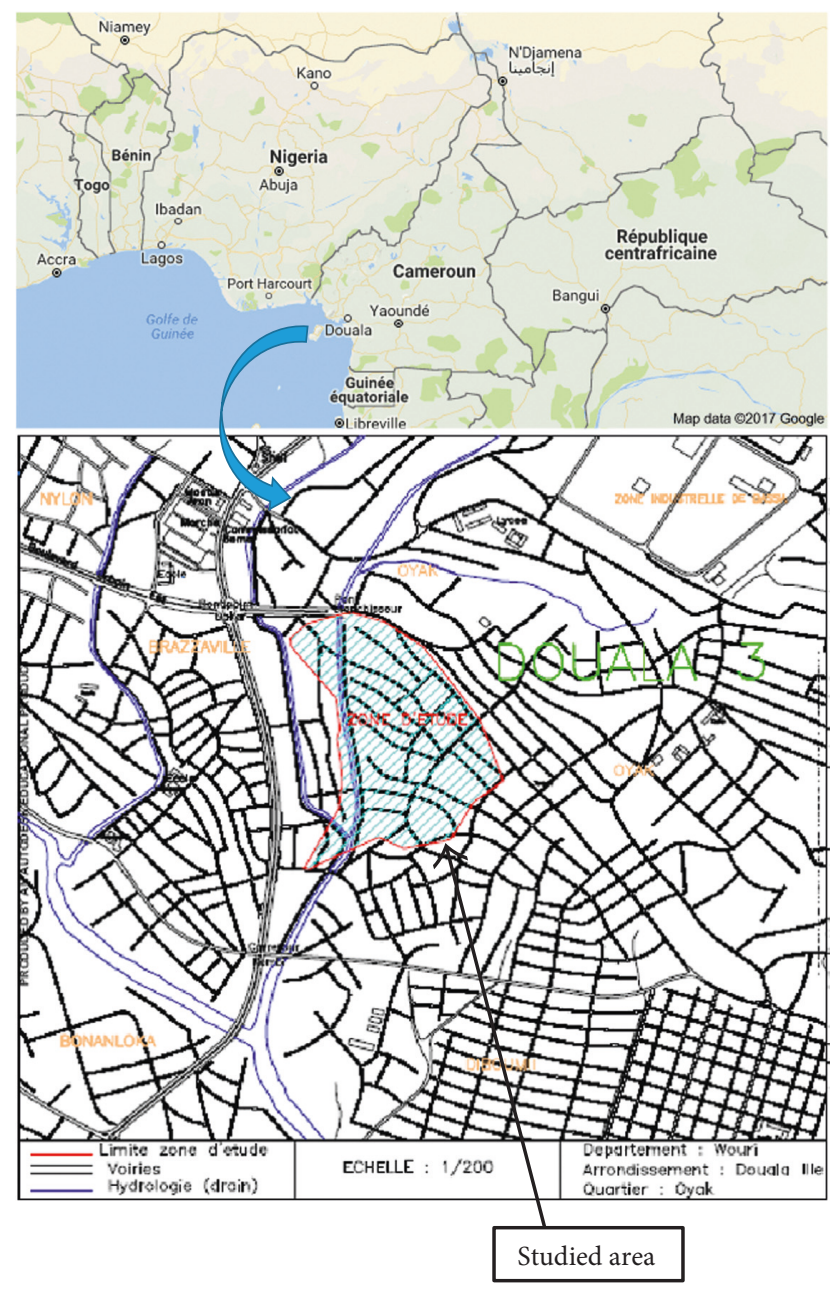

Figure 1: Study area map [8].

recognised by Hairsine and Hook [3] and Bryan [4]. The fundamental problem is to define the correlation between the rainfall intensity, the cohesion of soil, the hill slope, and the global volume of soil transported by water flow.

The present work aims to simulate the dynamics of soil erosion taking into account the three main parameters influencing the phenomenon: nature of soil (compaction), hill slope, and the rainfall intensity.

This type of rainfall simulator has already been used in many studies by Collinet and Valentin [5], Chaplot and Le Bissonnais [6], and Hamed et al. [7].

After describing the experimental apparatus together with the soil density, the experimental simulation is carried out, and the correlation between various experimental parameters is presented.

\section{Materials and Methods}

2.1. Geographical Location of the Study Area. Cameroon is physically between West and Central Africa at the far north east of Gulf of Guinea. It covers a surface of about $475.650 \mathrm{~km}^{2}$ and extends in triangle latitude between $2^{\circ}$ and $13^{\circ} \mathrm{N}$, extending from Gulf of Guinea to Lake Chad on a distance of about $1200 \mathrm{~km}$, and between longitude $8^{\circ}$ and $16^{\circ} \mathrm{E}$ on a distance of about $800 \mathrm{~km}$. The country is limited in the north by Lake Chad; in the south by the Republic of Congo, the Republic of Gabon, and Equatorial Guinea; and in the west by the Federal Republic of Nigeria and the Atlantic Ocean Coast on about $400 \mathrm{~km}$.

Nylon area is located in the municipality of the city district of Douala III, at the South East fringe of the agglomeration. The city district covers a surface of about $113 \mathrm{~km}^{2}$ for a population estimated to be $1,350,000$ inhabitants. Its base is at Logbaba. Nylon area is one of the more populous sectors in Douala town with 380,000 inhabitants. It is made of about fifteen quarters (Bilongue, Vie Tranquille, Oyack, Diboum, Ndogpassi, etc.) very precarious in their majority, far from down town, and underserved [8]. It is a swampy area which presents soil sufficiently saturated in water [9]. In the context of this study, the work will be made at the level of bloc III in Nylon area, as shown in Figure 1. The area of this bloc is around 24 ha 22 to $30 \mathrm{ca}$.

2.2. Presentation of the Minisimulator of Rain. The conception and realisation of the minisimulator of rain presented in Figure 2 has been conceived based on the one realised by Warlouzel [10]. This experimental design helps to take into account 3 phenomena: namely, rain, streaming, and combination of rain + streaming. These phenomena contribute to tearing and transport of strong eroded particles.

The NEME minisimulator of rain is a device that can simulate rainfall with different variabilities that are close to natural precipitation events. This device makes it possible to reproduce rainfall artificially and runoff over an area of $1 \mathrm{~m}^{2}$ taking into account the topography (slope), the intensity of rain (useful rain), the duration of the rainfall, the different phases of rain, and the soil structure. This test device consists of five parts: the structure, the streaming vat, the irrigation network, the tanks, and the motor pump.

The watering network is fixed at the top of the structure of $2.5 \mathrm{~m}$ high. Sprinkling is ensured by a watering system calibrated by valves mounted on a rectangular frame. The opening of the valves at predefined angles makes it possible to calibrate the rainfall intensities to be simulated on the study plot. A varied range of intensities are possible.

The water supply is provided by a motor pump. The installation of an overflow channel in the tanks to simulate runoff and rain keeps the water inlet pressure constant. The soil samples studied are contained in a streaming vat with two collectors: one that collects runoff water and the other that collects infiltrated water.

2.3. Experimental Protocol. To carry out this laboratory investigation campaign, samples of stirred soil of studied area were being removed and transported to the laboratory. After this, samples of soil are introduced into the streaming vat. After a first rain, left soil compacts itself for a period of two weeks. Those soil samples are submitted at the rhythm of rains, streaming, or the combination of rain + streaming. At 


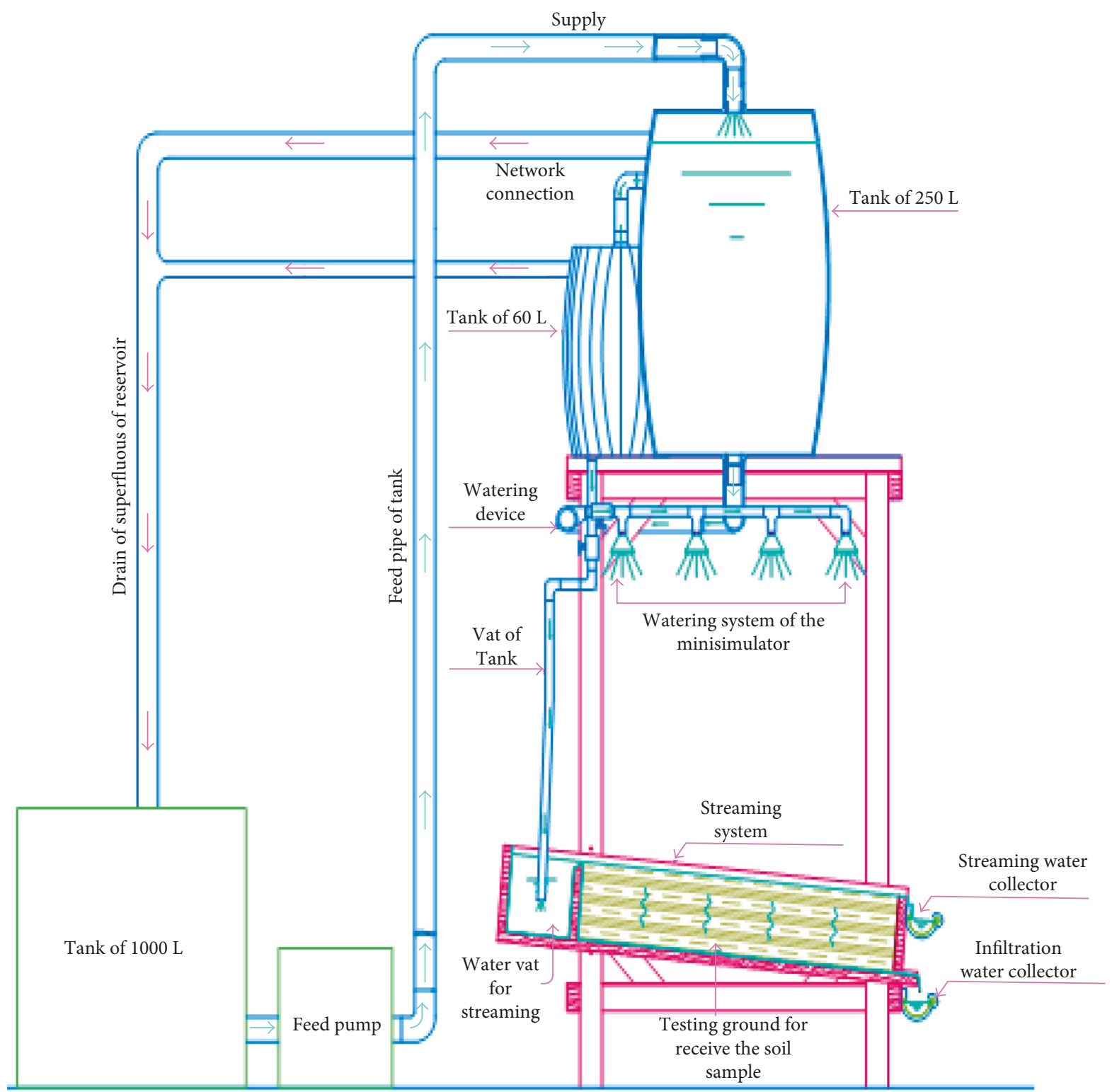

Rain minisimulator : descriptive schema

Figure 2: Operation design of the minisimulator.

a given soil sample, fixed pitch line, and flow rate, we simulate successively one of the phases (rain, streaming, and rain + streaming) during a duration of $20 \mathrm{~s}, 40 \mathrm{~s}$, and up to $120 \mathrm{~s}$. For each time period, pitch line, and flow rate, repeat the test eight times and then find the mass of soil eroded.

Mass of soil eroded is guessed with a digital scale (Figure 3).

The use of scale for the computation of masses eroded follows the protocol:

(i) Connect the scale

(ii) Calibrate the scale and ensure that the screen displays the value 00.000

(iii) Place the tare containing dried soil on scale and record the mass

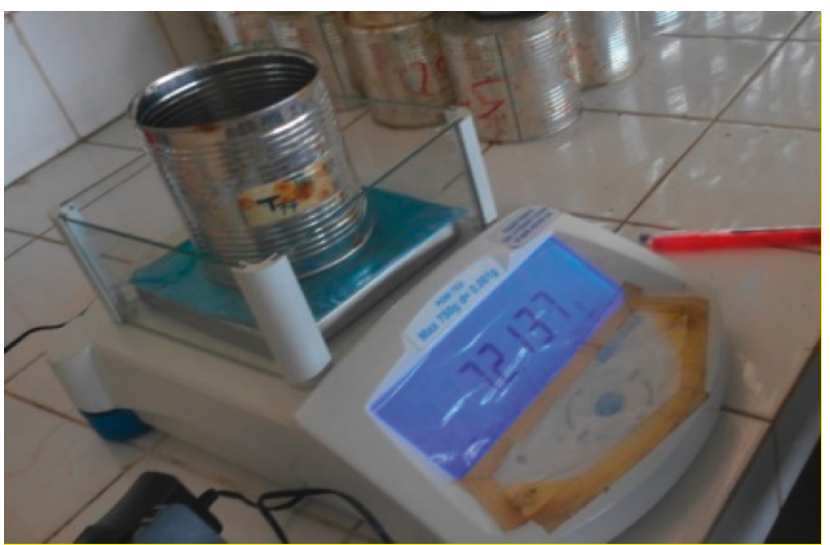

FIgURE 3: Scale measure of masses eroded (LAMMA). 
(iv) Remove dried soil from the scale, clean and weigh the empty tare, and record the mass

(v) Deduct net mass of the material by subtracting the mass of the tare from the total mass following the relation:

$$
m=m_{t}-m_{t a}(g)
$$

To bring simulation work to a conclusion, this protocol is used:

\subsection{Pretest Tasks}

(i) Fill with water the tank of $1000 \mathrm{~L}$

(ii) Install power pump

(iii) Fill power pump with sustain water before usage

(iv) Adjust streaming vat on the horizontal

(v) Adjust values of watering system of minisimulator at the desired openness $(1 / 2,1 / 6$, and $1 / 4)$

(vi) Start-up power pump and adjust its flow rate at the lowest level

\subsection{The Definitive Test}

(i) Adjust streaming vat at the desired slope $(0 \%, 2 \%$, and $4.37 \%$ )

(ii) Adjust values of minisimulator's watering system at the desired openness $(1 / 12,1 / 6$, and $1 / 4)$

(iii) Start the power pump and adjust its flow rate at the lowest level

(iv) Place the 3 technicians at their post (resp., on the timer, at valves opening, and at different collectors)

(v) Open simultaneously:

(1) Watering devices feed valve and the desired position (1/12, 1/6, and 1/4) knowing that secondary valves were settled preliminarily

(2) Streaming valves equally at the desired position $(1 / 12,1 / 6$, and $1 / 4)$

(3) Activating the stopwatch

(vi) During the conduct of the test:

(4) Collect streaming and seepage waters in builder buckets via collectors

(5) Transfer streaming waters in storage drums through the screen of 80 micrometers

(vii) After the pouring period expected $(20 \mathrm{~s}, 40 \mathrm{~s}, 60 \mathrm{~s}$, $80 \mathrm{~s}, 100 \mathrm{~s}$, and $120 \mathrm{~s}$ ):

(viii) Stop or close simultaneously:
(a) the stopwatch,
(b) the main valve,
(c) the streaming valve.

(ix) Collect eroded soil mass (oversize) and put it in a container or a tare therefor

(x) Transfer the volume of seepage water in a container (tare) therefor (xi) Write down numbers of different tares (eroded soil mass tare and seepage water tare) before storing them

(xii) Then, another test can be started

\subsection{Posttest Tasks}

(i) Settle streaming waters collected during a period of time found between 24 and 72 hours (depending on the quantity of water to be settled)

(ii) During settlement process, reduce through a screen of 2 micrometers the quantity of streaming water contained in the buckets

(iii) Once the settlement process completed, collect the material (undersized grains) and introduced into the corresponding tare, then weighed;

(iv) Weigh out the quantity of seepage inflow and write down its mass

(v) Dry the material collected using a vented oven at $105^{\circ} \mathrm{C}$ for a minimum period of 24 hours

(vi) Weigh out the dry material

(vii) Write down the number of the tare and the mass of the dry material

For the phases of rain and streaming taken separately, steps of protocol are identical with one difference. In fact, rather than opening simultaneously the main valve and the streaming valve at the desired position, open them independently each time with the desire to feign rainfall or streaming.

2.7. Method of Filtering Streaming Waters. In order to filter waters collected during different tests, the use of two large screens is needed: one of 80 micrometers and the other one of 2 micrometers.

The screen is placed on top of the tank. Pour the water coming directly from the streaming water collector into the screen of 80 micrometers in order to filter it. The screen retains soil particles of big sizes and permits the more tiny ones to pass, which are collected in the storage drum. Soil mass which remains in the screen is transferred in the numbered tares.

Particles which have passed through the screen of 80 micron are left to rest in storage drums for settlement. The settlement process consists of leaving suspended soil particles settle to the bottom of the storage drum. Filter through a screen of 2 micrometers the superficial part of the water contained in the storage drum after depositing (water runs clear). Repeat the process until obtaining undersized that is introduced in another tare.

Notice that tare mass is known in advance. Let us precise that the quantity of soil remained in the screen is called oversized and the one which passes through it up to complete settlement is called undersized. Following the filtering and the settlement process, let dried off and weigh out separately the masses obtained.

In the course of the different analysis, during the 45 first tests, dry mass of undersized represents $1.99 \%$ of oversized 
masses. By taking into account operator and accuracy errors of the rain simulator, the percentage of the undersize is worth $2 \%$ of the oversized masses (mass of undersized $=$ mass of oversized $\times 2 / 100$ ).

In order to save time in the following test, the choice made is to work directly with the oversized. Once oversized masses obtained, the total masses of soil eroded have to be determined. Total mass is therefore equal to the mass of oversized plus the mass of undersized $\left(M_{\text {total }}=M_{\text {oversized }}\right.$ $\left.(1+2 / 100)=M_{\text {oversized }} 1.02\right)$. This approach has permitted to do each test eight times in order to come out with the average. It is those average which intervene in the analysis of the study.

\subsection{Methods of Extrapolating Masses on the Study Area}

2.8.1. Extrapolating Principle. Based on the fact that without rainfall there is no water erosion, the main hypothesis of calculation of soil losses depends on rainfall. In fact, rainfall of the minisimulator of rain (Ps in $\mathrm{mm}$ ) is the average cumulated useful rain of the minisimulator. So, the rainfall of the minisimulator (Ps) corresponds a soil loss of the minisimulator $(\mathrm{Ms})$ in $\mathrm{t} / \mathrm{ha}$, and the annual rainfall $(\mathrm{Pa})$ corresponds equally an annual soil loss $(\mathrm{Ma})$ in $\mathrm{t} / \mathrm{ha} / \mathrm{annum}$, that is, $\mathrm{Ma}(\mathrm{t} / \mathrm{ha} / \mathrm{annum})=(\mathrm{Pa} \times \mathrm{Ms} / \mathrm{Ps})$.

2.8.2. Determination of the Real Surface of Bare Ground on the Study Area. This method permits to project results obtained in the course of experience on the study area. The studied area has a surface of 24 ha 22 to 30 a. It is an area made of irregular relief and inhabited by populations, to determine the percentage of occupancy of land squared a space measuring $1125 \mathrm{~m} \times 860 \mathrm{~m}$ was done. Following up, they have counted 750 living houses for which the total surfaces of roofs were estimated to be $762515.78 \mathrm{~m}^{2}$ over a total surface of $967500 \mathrm{~m}^{2}$. The fraction of surface of roofs divided by the total surface of the squared space gives $78.81 \%$. The space exposed to erosion after each rainfall is therefore $21.19 \%$ of the surface of the chosen study field, that is, 5.13 ha.

2.8.3. Quantification of Erosion in t/ha/annum. The average mass of soil eroded is the average of masses of soil eroded of all tests. Given that test has been realised on a surface of $1 \mathrm{~m}^{2}$ and that masses are expressed in gram, our average soil loss on the minisimulator is expressed in grams per square meter $\left(\mathrm{g} / \mathrm{m}^{2}\right)$. It is, however, possible to convert this later in $\mathrm{t} / \mathrm{ha}$. Notice that, in this study, rainfalls of the simulator of rain (Ps) are $9179.55 \mathrm{~mm}$. This value can fluctuate depending on the type of tests made on the minisimulator of rain.

According to Kemajou [11], annual rainfalls of Douala town are $4190 \mathrm{~mm} / \mathrm{annum}$. Once essential elements are available, it is possible to simply apply the principle of extrapolating listed above. Therefore, soil loss or potential of erosion is expressed in $\mathrm{t} / \mathrm{ha} /$ annum. From this result, determination of total quantity of soil transported in t/annum over a given surface is possible, by multiplying the erosion rate by the real surface of soil exposed. To confirm the result of the minisimulator, make calculation of soil loss with the USLE relation

$$
(A=R \times K \times L S \times P \times C) .
$$

\section{Results and Discussions}

3.1. Results. The study was made on 2 sample ranges, and interpretations presented are of way of example and illustration. Presentation of results and interpretations of some tests simulated on sample 1 will be applied subsequently in the work to other tests and samples. Conclusions will take into account phases of tests, namely, a phase of rain simulation, a phase of streaming simulation, a combined phase of rain + streaming. All the diagrams (figure 4 to figure 11) have been traced with Matlab 2015a software.

3.1.1. Simple Rain Phase. Simple rain simulation phase allows to obtain the results represented in Figures 4 and 5 .

Figure 4 shows that, on all columns of time, maximum masses eroded are obtained at the slope of $4.37 \%$ and those maximum masses increase with time until they reach the maximum erosion of a value of $69.67 \mathrm{~g}$ obtained after a duration of $120 \mathrm{~s}$. In a general way, on the three pitch lines of slopes, masses of soil eroded increase according to time. On each column of time, masses of soil eroded increase with slopes. For this flow rate, masses of soil eroded are very low for slopes of $0 \%$ and $2 \%$.

Masses of soil eroded obtained at the slope of $4.37 \%$ are almost three times greater than those obtained for slopes of $0 \%$ and $2 \%$. A general overview of diagrams obtained during the different phases of tests at a flow rate of $0.10 \mathrm{~L} / \mathrm{s}$ permits to conclude that the slope has an influence on erosion process [12].

For a flow rate of $1.20 \mathrm{~L} / \mathrm{s}$, the results are represented in Figure 5.

Figure 5 shows that on all the six columns, masses of soil eroded increase from the slope $0 \%$ to the one of $4.37 \%$. Following, on different lines of the slope, masses of soil eroded increase according to time. Maximal erosion of soil eroded is realised at the slope of $4.37 \%$ and worth $340.94 \mathrm{~g}$ in the course of period of test of $120 \mathrm{~s}$. For this phase of rain, the conclusion is that masses of soil moved increase with the slope and time. For tests realised with a flow rate of $0.1 \mathrm{~L} / \mathrm{s}$, a maximum of soil moved equals $80 \mathrm{~g}$ obtained at the slope of $4.37 \%$ after 120 seconds of simulated rain. For a flow rate twelve times higher than this later, a maximum of soil moved of $400 \mathrm{~g}$ is five times the one obtained at the previous flow rate. Consequently, it follows that rain intensity has a real impact on the deterioration of soils and their transport toward lowest depths. Erosion potential helps in reaching a result not far from the one proposed by Garouani et al. [13].

Following the rain phase, the next step is with streaming simulation phase.

3.1.2. Streaming Phase. This phase takes into account only streaming. Results showing masses of soil eroded according to the slope and time of simulation are presented in Figures 6 and 7. 


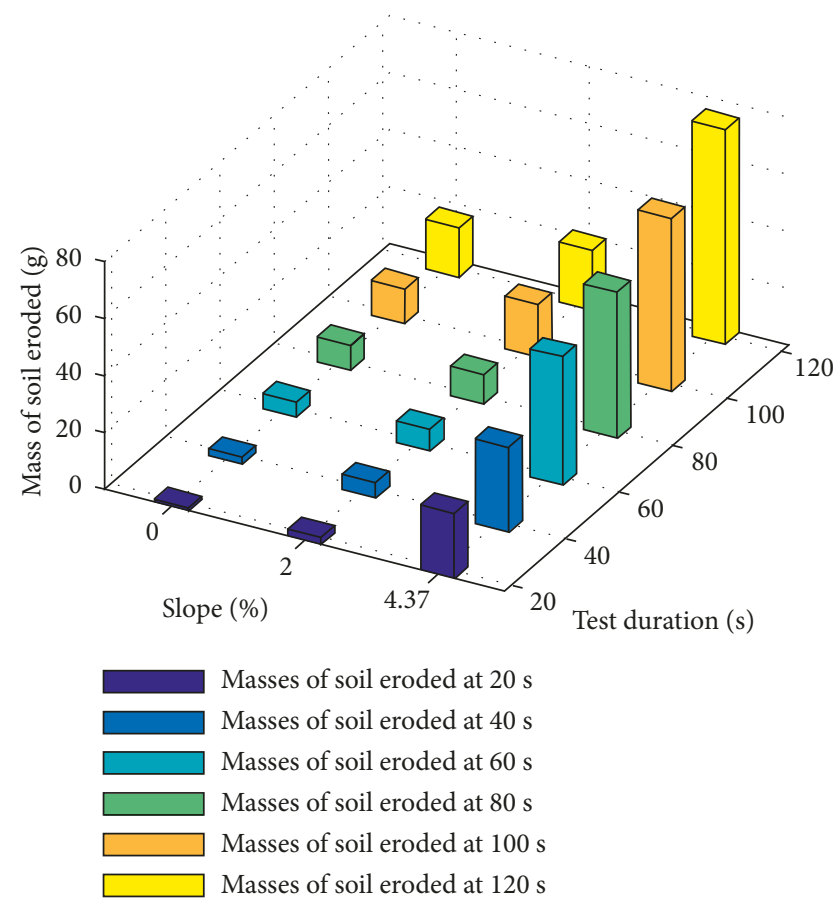

FIGURE 4: Diagrams of masses of soil eroded at a flow rate of $0.10 \mathrm{~L} / \mathrm{s}$ on the sample.

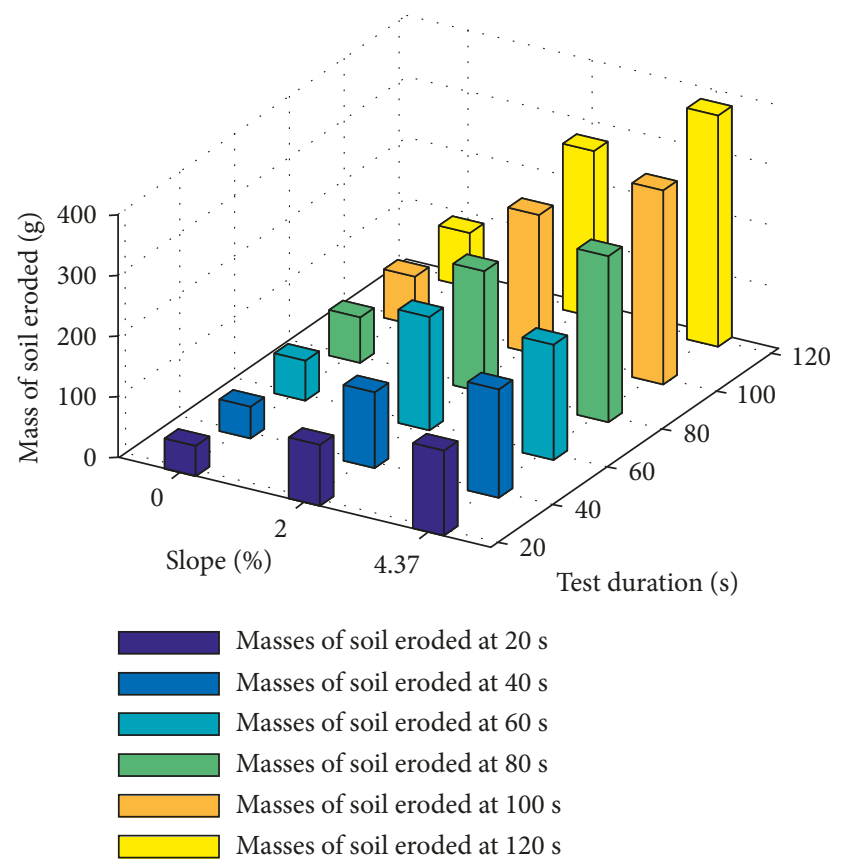

FIGURE 5: Diagrams of masses of soil eroded at a flow rate of $1.20 \mathrm{~L} / \mathrm{s}$.

This part has only two flow rates. The lowest flow rate which is kept constant at $Q=0.04 \mathrm{~L} / \mathrm{s}$. An analysis of Figure 5 helps us to notice that, on the different columns, masses of soil eroded increase according to the slope and reach their maxima at the slope of $4.37 \%$. However, masses of soil eroded on pitch lines of $0 \%, 2 \%$, and $4.37 \%$ evolve in an increasing manner according to time. However, on the pitch

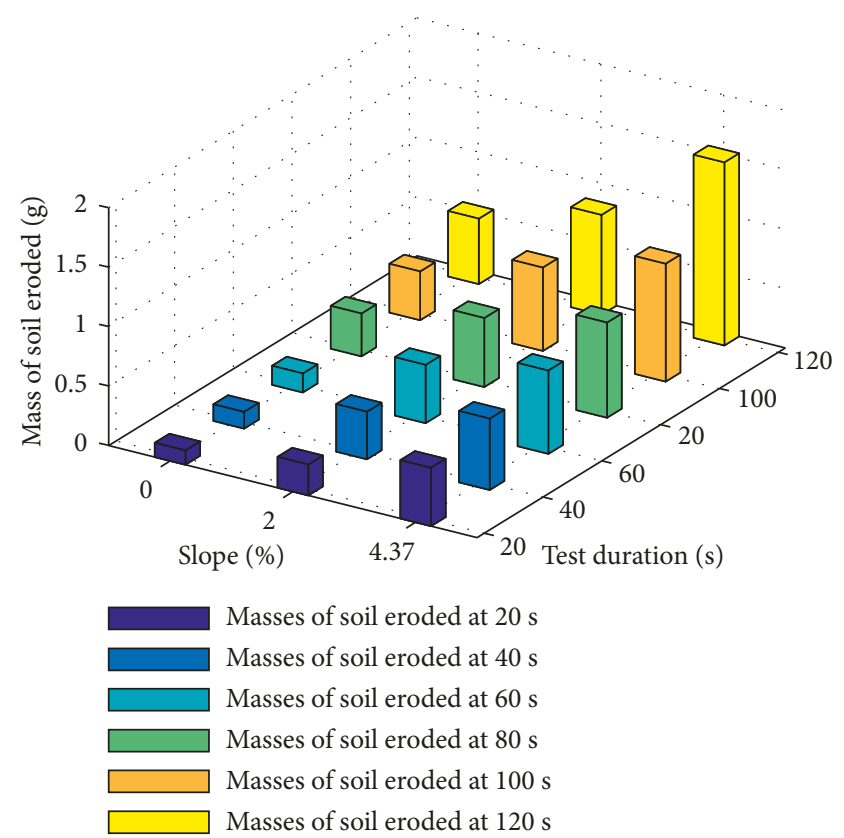

Figure 6: Diagrams of masses of soil eroded at a flow rate of $0.04 \mathrm{~L} / \mathrm{s}$.

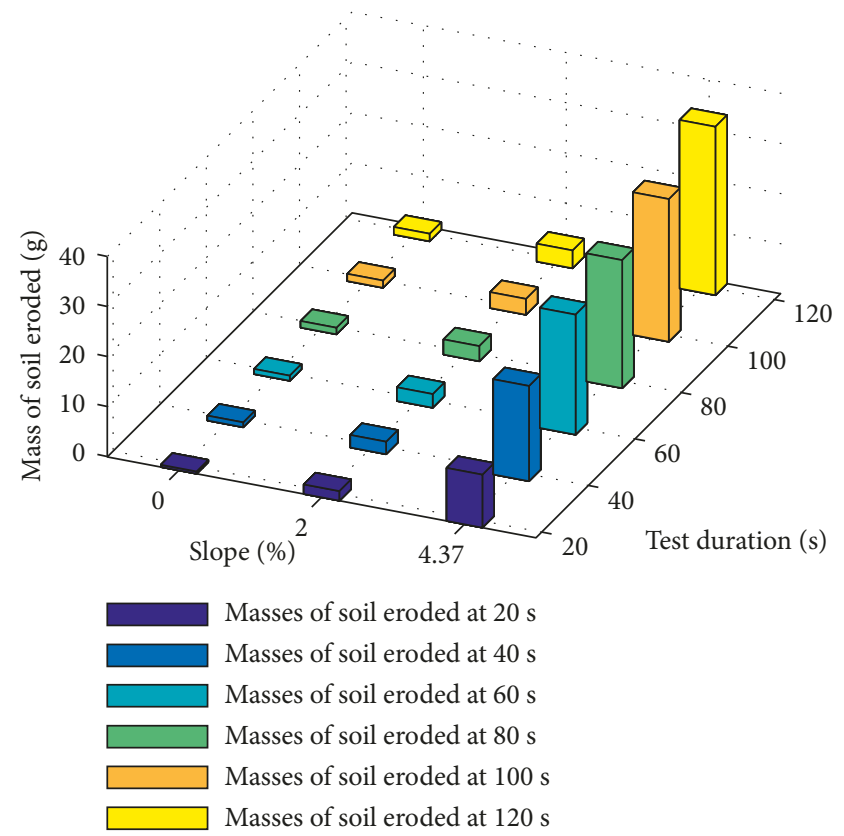

Figure 7: Diagrams of masses of soil eroded at a flow rate of $0.2 \mathrm{~L} / \mathrm{s}$.

lines of $4.37 \%$, masses of soil eroded are more important than those on the other pitch lines, maximal erosion of soil is obtained after $120 \mathrm{~s}$ of rain simulation at the slope of $4.37 \%$ and has a value of $2.21 \mathrm{~g}$. In conclusion, masses of soil eroded are very low. This is justified by the fact that the flow rate is very weak. Consequently, streaming cannot disintegrate and transport solid particles of a precise diameter.

For a flow rate of $0.20 \mathrm{~L} / \mathrm{s}$, results are presented in the diagram of Figure 7. 


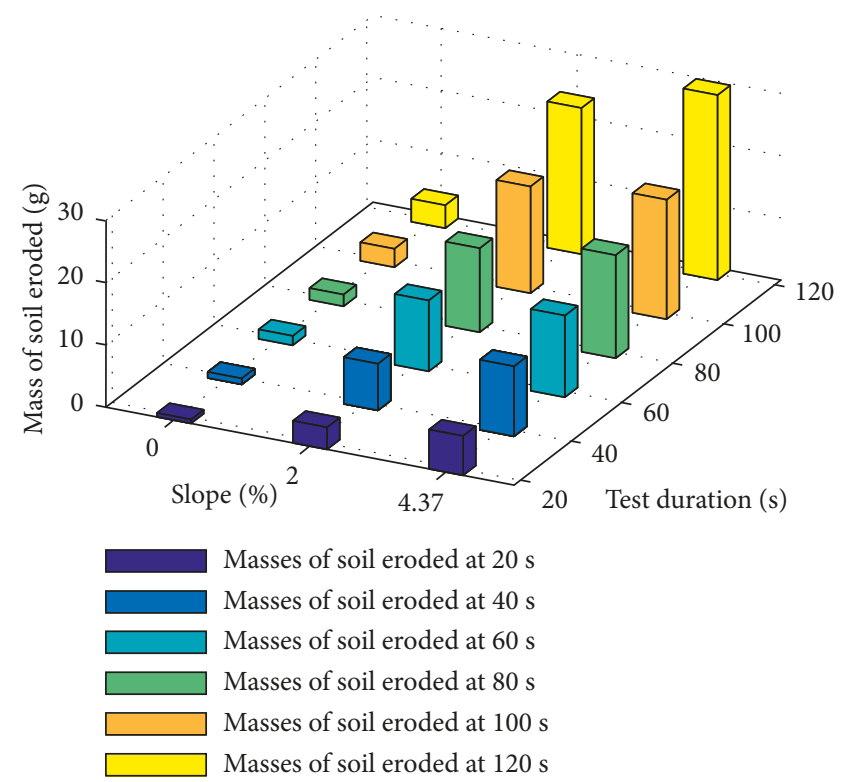

FIGURE 8: Diagrams of masses of soil eroded at a flow rate of $0.13 \mathrm{~L} / \mathrm{s}$.

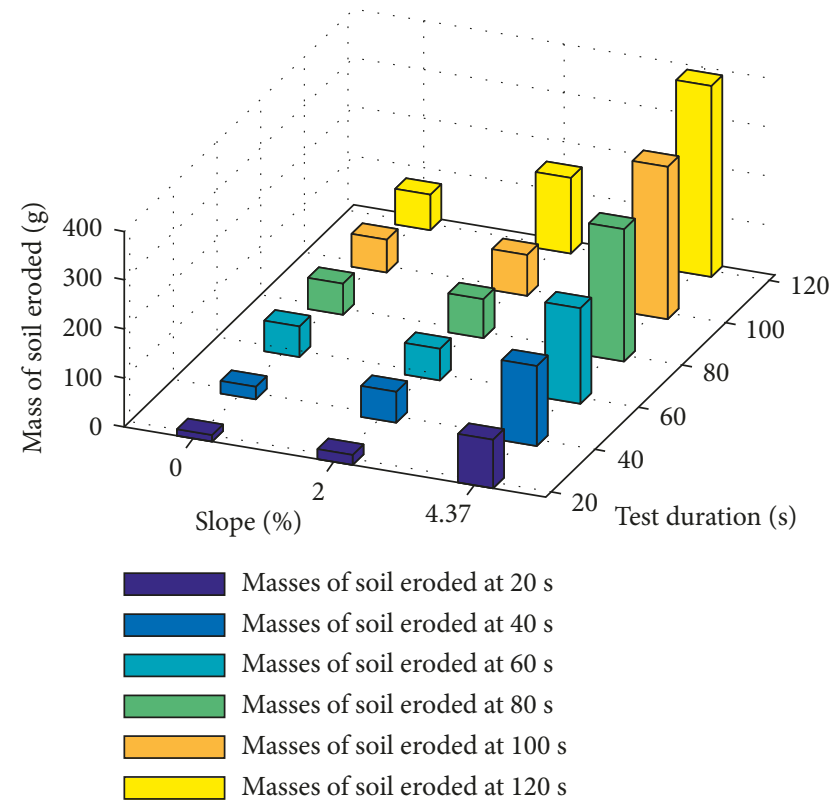

Figure 9: Diagrams of masses of soil eroded at a flow rate of $0.575 \mathrm{~L} / \mathrm{s}$.

By considering this last test of streaming phase, our flow rate is fixed at $Q=0.20 \mathrm{~L} / \mathrm{s}$. Other parameters like duration of test and slope are varying. On the six columns of time, masses of soil eroded increase with slopes. Masses of maximal soil eroded are all realised at the slope of $4.37 \%$. Maximum eroded land masses are all made with the slope of $4.37 \%$. It is therefore possible to conclude that, for simple streaming tests, masses of soil transported are proportional to blade of streamed waters. It is the case only of streaming. In addition, maximal masses of soil eroded at a flow rate of $0.20 \mathrm{~L} / \mathrm{s}$ are largely higher than those eroded at a flow rate of $0.04 \mathrm{~L} / \mathrm{s}$.

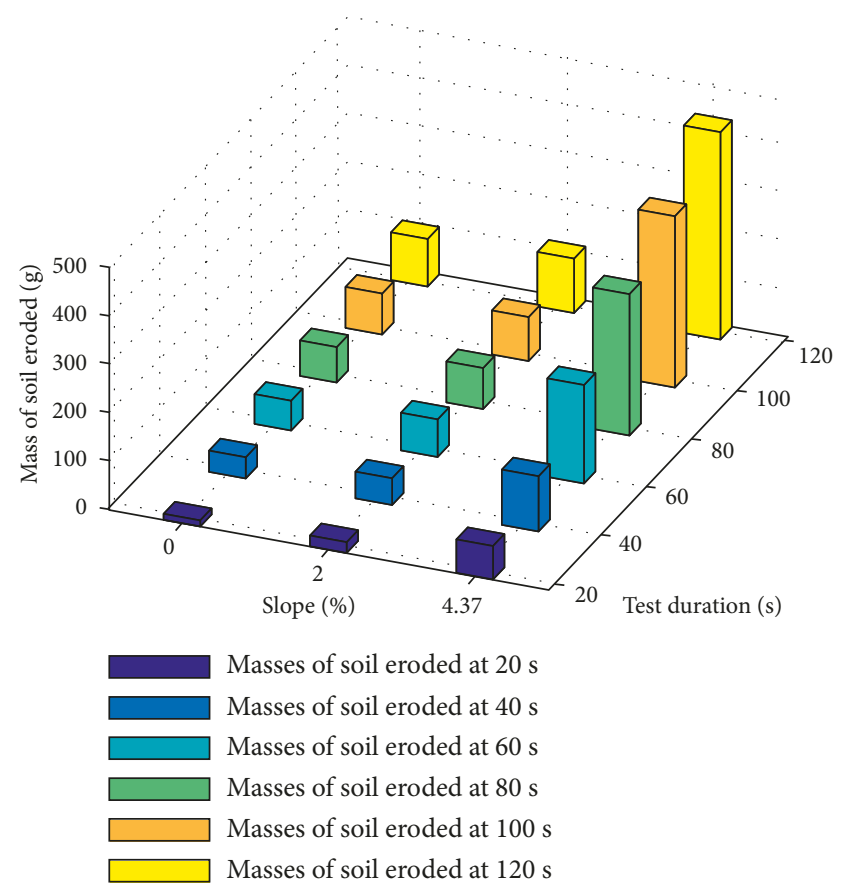

FIgURE 10: Diagrams masses of soil eroded at a flow rate of $0.725 \mathrm{~L} / \mathrm{s}$

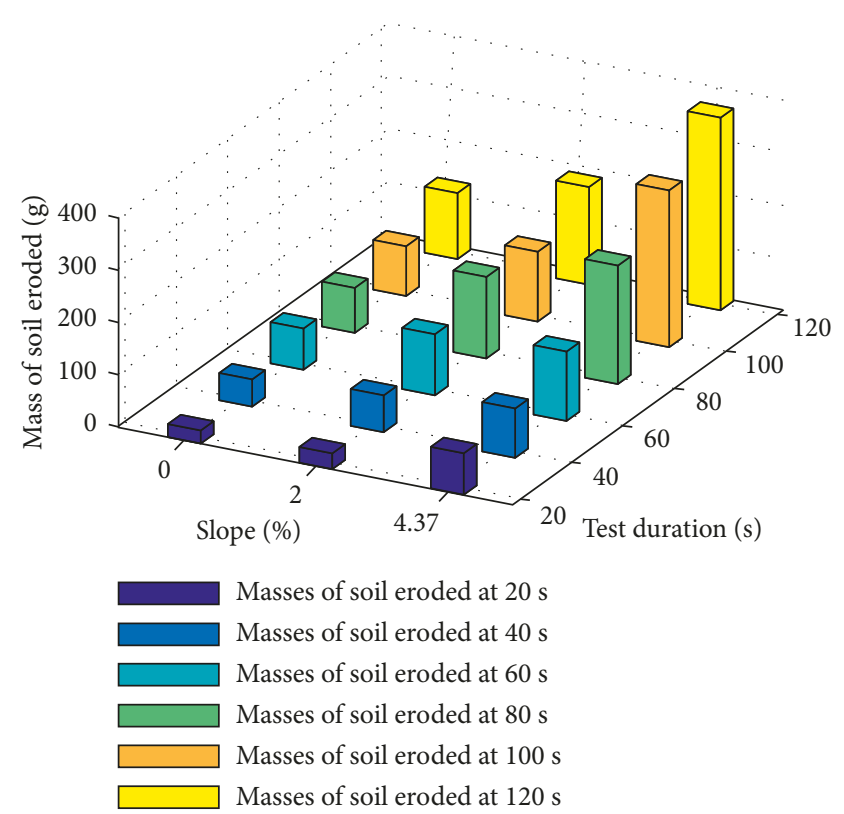

FIgURE 11: Diagrams of masses of soil eroded at a flow rate of $1.4 \mathrm{~L} / \mathrm{s}$.

Once the two first phases of simulation presented, the attention is now focused on the simulation on the combination of rain + streaming.

3.1.3. Rain + Streaming Phase. For this phase, four flow rates: $0.13,0.575,0.725$, and $1.4 \mathrm{~L} / \mathrm{s}$, were chosen. Masses of soil eroded for each one of these four flow rates, slopes, and simulation times are represented in Figures 8-11. 
Figure 8 shows that, on columns of 20 s, 40 s, 60 s, 80 s, $100 \mathrm{~s}$, and $120 \mathrm{~s}$, masses of soil eroded increase with slopes and reach their maximum at the slope of $4.37 \%$. Masses of soil eroded on pitch lines $(0 \%, 2 \%$, and $4.37 \%)$ increase according to time. This situation reveals that maximal erosion of soil eroded of this test is $24.480 \mathrm{~g}$ obtained at the slope of $4.37 \%$ after a time period of $120 \mathrm{~s}$ of rain simulation. In Figure 8, masses of soil eroded on the pitch line of $0 \%$ after $100 \mathrm{~s}$ of simulation are very low compared to the other pitch lines.

Concerning flow rates of $0.575 \mathrm{~L} / \mathrm{s}$, results are presented in Figure 9.

Analysis of different columns shows that masses of soil eroded on the six columns of time increase according to slopes and reach their maximum at the slope of $4.37 \%$. Long slopes generally result in high amounts of soil loss [14, 15]. Masses of soil eroded on the three pitch lines $0 \%, 2 \%$, and $4.37 \%$ evolve over time. It is possible to deduct that maximal erosion of this first test inferred to be met at the slope of $4.37 \%$ after a time period of $120 \mathrm{~s}$ of simulation and worth $330.756 \mathrm{~g}$. In the previous test, we have obtained a maximum of soil moved of $24.480 \mathrm{~g}$ with a flow rate of $0.13 \mathrm{~L} / \mathrm{s}$. For a flow four times larger, we obtain a quantity of sediment thirteen times larger. After many rainfalls of such intensity, soil disappearance phenomenon is a reality.

Reached to a flow rate of $0.725 \mathrm{~L} / \mathrm{s}$, results are illustrated in the diagram of Figure 10.

Maximal masses eroded on all the lines are obtained at the slope of $4.37 \%$. On the different columns of time, masses of soil eroded increase with the slope and reach their maxima on the slope of $4.37 \%$. On the opposite, on pitch lines $0 \%$, $2 \%$, and $4.37 \%$, masses of soil eroded increase according to time. Maximal erosion is reached at the slope of $4.37 \%$ after a time period of $120 \mathrm{~s}$ and has a value of $396.26 \mathrm{~g}$. Compared to the previous test, the gap of sediments transported between the two maxima is not so important. Higher the flow rate, higher the useful rain. Climate change models predict, greater erosion rates [16-18]. More rain is important, thicker the streamed blade. It is even the case of the study area where soils are saturated by water [9]. The more the run-off blade is thick, the more the effect of rainfall on the soil is reduced. Streamed blades of a certain thickness form screens and do not permit disintegration and transport of solid particles. It is possible to conclude that the slope does not necessarily help erodibility of soils but contribute to accelerate the movement of solid particles eroded toward lowest depths of watershed. Like in the previous test, the chosen flow rate favorised an important erosion of soil.

For this last flow rate of rain + streaming phase, data collected on the simulator of rain in laboratory have permitted to get results presented in the diagram of Figure 11.

In this last part of rain + streaming phase, the flow rate is $Q=1.4 \mathrm{~L} / \mathrm{s}$. Slopes and time period of test remain variables. By examining accurately, the six columns present their maximal erosion at the slope of $4.37 \%$. However, masses of soil eroded on different pitch lines increase with time. Maximal erosion is reached at a slope of the $4.37 \%$ for a time period of $120 \mathrm{~s}$ of simulation and worth $317.49 \mathrm{~g}$. Following these observations, it is possible to comfort ourselves on the idea that the flow rate which produces the maximum of soil eroded is $0.725 \mathrm{~L} / \mathrm{s}$. For a flow rate of $1.4 \mathrm{~L} / \mathrm{s}$, screen effect is more perceptible. Taking into account the nature of soils (saturated) of the study area, the thickness of the streamed blade increases quickly with time period of this later. According to Pacheco et al. [19], Centeri et al. [20], Evans [21, 22], and Valle et al. [23], soil erosion is further aggravated by environmental land-use conflicts (ELUCs).

Formation of concentrated flow is strongly dependent on the spatial connectivity of runoff and sediment sources across point $\left(<1 \mathrm{~m}^{2}\right)$ to patch scales (10 s square meters) [24-27].

Reaching the end of this phase of test which corresponds to the rain + streaming phase, the conclusion is that it would not be possible to define mathematic model which will describe evolution of masses of soil eroded according to the time, the slope, and the flow rates.

In short, for all tests of the two sampling phases, the authors noticed that, in the simple rain phase, maximal erosion has been realised at the slope of $4.37 \%$ for all flow rates. This can be explained by the fact that weight of the streamed blade will help bolster soils disintegrating dynamic and transport of particles of important sizes.

Then, for simple streaming tests, masses of soil transported are proportional to stream of water blades. It is the exclusive case of streaming. They could equally observe that maximal masses of soil eroded at a flow rate of $0.20 \mathrm{~L} / \mathrm{s}$ are ten times higher than those eroded for $Q=0.04 \mathrm{~L} / \mathrm{s}$.

Finally, in the case of combined rain and streaming tests, they comfort themselves on the idea that flow rates which produce maximum of soil eroded are $0.575 \mathrm{~L} / \mathrm{s}$ and $0.725 \mathrm{~L} / \mathrm{s}$. In addition, on the test of rain + streaming phase, they notice that every tests realised that their maximum of soil eroded always at the slope of $4.37 \%$.

Comparison of masses of soil eroded at the rain + streaming phase and associated phases is made for every flow rate and on all slopes of the two sampling phases. In fact, to reduce the number of figures, some of them have been chosen as illustration. It should be noted here that findings of this comparison take into account all details of different figures of the two samplings.

Table 1 represents the sum of masses eroded of different rain simulation phases and highlights the superiority of the one on the other. Table 1 is equally useful as base for potential erosion calculation.

Table 1 shows that the average mass of soil eroded is $33,645.094$ gram, for an average time period of 17,640 seconds on a surface of $1 \mathrm{~m}^{2}$, that is, $336.45 \mathrm{t} / \mathrm{h}$ for a rainfall of $9179.55 \mathrm{~mm}$.

3.1.4. Comparison of Laboratory Results with Those Obtained from the USLE Relationship. As a first step, it is important to calculate the erosion potential obtained on the minisimulator. Calculation of the rate of erosion on one hectare gives $153.57 \mathrm{t} / \mathrm{ha} / \mathrm{annum}$. Extrapolation on the exposed surface of the chosen study field helps to get a rate of erosion of $788.12 \mathrm{t} /$ annum. In order to compare the results obtained on the minisimulator, the calculation of the erosion potential and the extrapolation of the result over the entire study area are needed. The USLE relation is defined by 
TABLE 1: Average masses eroded of the two sampling.

\begin{tabular}{lcccc}
\hline \multirow{2}{*}{ Sampling } & \multicolumn{2}{c}{ Total time period of tests (second) } & \multicolumn{3}{c}{ Masses of soil eroded (gram) } \\
& & Simple rain & Simple streaming & Rain + streaming \\
\hline Sampling year 1 & 17,640 & 5177.541 & 164.101 & 9842.438 \\
Sampling year 2 & 17,640 & 5821.34 & 175.017 & $32,824.08$ \\
Average & 17,640 & 5499.441 & 169.559 & $10,829.75$ \\
\hline
\end{tabular}

$$
A=K * R * L S * C * P,
$$

where $A$ is the average annual soil losses possible on the long run ( $\left.\mathrm{tha}^{-1} \mathrm{yr}^{-1}\right), R$ is the index erosivity of rains (MJ mm/hahan), $K$ is the index of soil erodibility ( $\mathrm{thah}$ ha $\mathrm{MJ} \mathrm{mm}$ ), LS is the slope factor (adimensional), $P$ is the Brace pattern factor (adimensional), and $C$ is the vegetation factor (adimensional).

USLE relation helps us to get a rate of erosion of $999.51 \mathrm{t} /$ annum, that is, $159.02 \mathrm{t} / \mathrm{ha} / \mathrm{an}$. The results obtained by the relations of USLE and RUSLE are less satisfactory $[28,29]$.

In order to validate the results obtained on the minisimulator, two methods for measuring and estimating water erosion are identified. In conclusion, it is a question of comparing these approaches and, in particular, the measurements on the rain simulator and the measurements carried out at the outlet of the watershed through the relation of USLE. Under artificial rainfall using a rainfall simulator, under controlled conditions (water level and precipitation intensities close to natural conditions, and control of other parameters: slope, simulation time, etc.), this experimental setup proves to be very useful for rapid information on infiltration dynamics and runoff risks, on the relationships between soil losses and slope, or on different weather conditions in rain simulation. However, a number of manipulations between 5 and 10 may be necessary to validate the results, with an acceptable level of confidence. In parallel, a prediction equation, the universal soil loss equation (USLE), based on the study of 10,000 annual measurements of plot erosion, was developed by Mabit et al. [30] and Wischmeier and Smith [31]. The latter has been used worldwide because it is very practical, and its limits have been emphasized since the end of the 1970s. The use of this model must be strictly limited to the scale field whose slopes are less than 20\%. Erosive processes have been conducted at the watershed scale as they are functional units for systemic consideration of the water cycle and internal flows [32]. The relevance of this scale of study makes it possible to take into account and integrate the stable characteristics of the medium and the variable parameters, on short time steps (seasonal, annual, or multiyear) [33].

This method, therefore, makes possible a coupled study of water and soil resources. Only the aspect of estimating earth losses was considered. This approach is subject to annual and interannual climate variability. This consideration of climatic variability requires further research over many years. Earth loss measurements are only representative of the year of study, or the amount of time allowed [30]. On the other hand, this approach makes it possible to measure the losses in earth that actually leave the site. Indeed, the annual report of losses in land, related to the functioning of watersheds, conceals temporal discontinuities [33].

The different methodologies presented, which each have their fields of application and their limits, appear complementary. The choice of one of them and/or their coupling must be made according to the problem and the research objectives.

Rainwater in a very simple pattern (splash-splashed soil particles-runoff-sediments exported) contributes to the degradation and transportation of bare soil from one place to another. This mass transport of solid particles along privileged directions simultaneously contributes to the denudation of the foundations of dwellings located in the upstream zones of the watersheds, to the weakening and the degradation of structures and superstructures, to the burial of the lowlands, and to siltation of watersheds. Since the study area is not agricultural, human action has been neglected. Depending on whether rainfall is low, medium, or high, this phenomenon can take on worrying proportions and cause enormous damage in urban areas. As part of this work, the study of the structural stability of soils made it possible to determine the erosive potential. These values, $153.57 \mathrm{t} / \mathrm{ha} / \mathrm{annum}$ (in vitro) and $159.02 \mathrm{t} / \mathrm{ha}$ /annum through the USLE relationship, represent the quantities of displaced sediments that have contributed to burying the watersheds and silting the various watersheds. These results reflect the reality on the ground and show that rain, topography, texture, and soil density are the main drivers of erosion.

Over the years, if we assume that these erosive potentials remain constant and grow over time, in a very short time, it would be possible to observe the foundations of completely naked dwellings, structures, and superstructures started to weaken and houses that are completely covered in the shallows and watersheds sufficiently silted.

3.2. Discussions. By analysing some computational works of soil loss quantification, we notice that methods used are not necessarily the same and study areas are distinct.

Study of quantification of water erosion from N'FIS watershed to high Atlas Mountains of Marrakech, Morocco, by using RUSLE model integrated to SIG [34-36] helps in classifying erosion potential in four classes.

By comparing this result to the one obtained in the course of this work, $153.57 \mathrm{t} / \mathrm{ha} / \mathrm{annum}$, it is validated and classified in the category which includes areas with potential erosion between 67 and $172 \mathrm{t} / \mathrm{ha} /$ annum.

Studies done by Bep et al. [37] show that soil loss is evaluated from 6 to $46 \mathrm{t} / \mathrm{ha}$ /annum for ferruginous-sandtropical soils of North Cameroon submitted to various cultural technics. The difference in results is explained by the fact that studied plots are cultivated, and that intensities and 
successions of rainfall events are not so important than those of the town in which our study has been made.

Equally, another study realised in the basin of Western Tlata, Morocco, with RUSLE model has given results very close to previous ones [13].

Mohamed et al. [38] in their studies have obtained results which vary from 50 to $400 \mathrm{t} / \mathrm{ha}$ /annum. Those results testify of high soil erosion greater than tolerance threshold.

Adam Kertesz [39] has published an article which has helped him to evaluate the average soil loss of $5.25 \mathrm{t} / \mathrm{ha} / \mathrm{annum}$. Comparison of this result to the one obtained in the course of this study helps to realise that climatological realities and soils textures are different.

According to a study of quantification of soil loss realised by Raissouni et al. [40], Palmer and Smith [41], and Prasuhn [42], unequal distribution of high-risk areas in basins results from the variability of feature of factors involved in the process and the model used. Definitely, USLE equation has been conceived to be simple and easy to use.

By observing objectivities and effectiveness limits of other assessment methods of erosion, we have put in place a minisimulator of rain which presents many benefit and usage possibilities. The minisimulator has been named NEME of LAMMA. Firstly, the minisimulator of the rain type NEME has the capacity to receive a soil sample of a surface of $1 \mathrm{~m}^{2}$ to a depth of $0.2 \mathrm{~m}$ and more. This sample can be compacted or not. In fact, for a soil sample, this one can be developed in streaming bench.

Secondly, the minisimulator of rain gives a possibility to produce three phases: namely, simple rain phase, streaming phase, and rain + streaming phase.

Thirdly, minisimulator of rain offers a large spectrum of rain intensity from the lower to the more devastating ones. To control the volume spilled, four flow rates over nine possibilities were retained for the simple rain phase. Streaming phase presents three different rain intensities. For the rain + streaming phase, eight flow rates over twenty seven possibilities were retained.

Fourthly, our design equally offers a possibility to vary the slope from zero to more than $70 \%$. Variation of slopes depends on the objective of the research.

Fifthly, the use of minisimulator of rain has the possibility to collect infiltrated and streamed water after each test. Different waters are collected via seepage and streaming collectors. The minisimulator is easy to manipulate and does not ask lot of resources. Anyone wishing to use it can manufacture it directly (by themselves).

Finally, the more important is that it offers another computational method of soil loss. This method has the advantage of making intervene the majority of factors involved in the study of the erosion phenomenon.

\section{Conclusion}

Study of erosion phenomenon in the area of Nylon, Douala, the Estuary of Wouri, has helped us to make analysis of different parameters which contribute to erosion phenomenon as well as quantitative assessment of water erosion in that region. These show a great weakness of these environments.
This study has also helped us to try a method of soil loss quantification through the minisimulator of the rain type NEME. This method has given results close to the one obtained by USLE in the same study area. It is good to notice that the studies were done on the minisimulator of rain at the maximal slope of $4.37 \%$ (relief realities considered).

Results obtained help in assessing masses of soils which move under the effect of rainfalls and help firstly in stripping foundations of homes upstream the study area and then to the disappearance of those in the lowest depths.

Saturation of soils of the study area in water constitutes an element which causes difficulties in the stability of these ones and promotes massive movement of sediments toward lowest depths. Consideration of maximal slopes over long distances could help highlight erosiveness of soils in sites presenting similar characteristics. Among the factors that cause soil erosion is poor land management, which causes damage to the soil and results in water runoff across landscape instead of adequate infiltration [43-46].

However, the design offers variably of slope up to a considerable value. For a very good performance of the minisimulator of rain, it is recommended studies to be carried out to improve and automate some functions of this one.

In a general way, erosion phenomenon is a very complex subject which requires numerous studies in order to enable an accurate determination of soil losses on a surface and to predict volumes moved due to rainfalls.

\section{Nomenclature}

A: $\quad$ Average annual soil losses possible on the long run (t.ha.annum)

$R: \quad$ Index erosivity of rains (MJ.mm/ha.h.an)

K: $\quad$ Index of soil erodibility (t.ha.h/ha.MJ.mm)

LS: $\quad$ Slope factor (adimensional)

$P: \quad$ Brace pattern factor (adimensional)

C: $\quad$ Vegetation factor (adimensional)

Ps: $\quad$ Simulated rain

Ms: $\quad$ Soil loss of minisimulator

Pa: $\quad$ Annual rainfalls

Ma: Annual soil loss

Q: $\quad$ Flow rate if water released

Li: $\quad$ Infiltrated water blade (L)

Lr: $\quad$ Streamed water blade (L)

$\mathrm{m}: \quad$ Masses of soil eroded (g)

GIS: Geographical information system

USLE: Universal soil loss erosion

NEME: Njeugna Ebénézer and Mbiakouo Eric

LAMMA: Laboratory of Mechanics and Adapted Materials.

\section{Conflicts of Interest}

The authors declare that there are no conflicts of interest regarding the publication of this paper.

\section{References}

[1] W. H. Wischmeier, "A rainfall erosion index for a universal soil-loss equation," Soil Science Society of America Proceedings, vol. 23, pp. 246-249, 1959. 
[2] W. H. Wischmeier and D. D. Smith, "Predicting rainfall erosion losses: a guide to conservation planning," US Department of Agriculture, Agricultural Handbook, No. 537, Science and Education Administration, Washington, DC, USA, 1978.

[3] P. B. Hairsine and R. A. Hook, "Relating soil erosion by water to the nature of the soil surface," in Second International Symposium on Sealing, Crusting and Hard setting Soils: Productivity and Conservation, H. B. So, G. D. Smith, S. R. Raine, B. M. Schafer, and R. J. Loch, Eds., pp. 77-91, Australian Society of Soil, University of Queensland, Brisbane, Australia, 1994.

[4] R. B. Bryan, "Soil erodibility and processes of water erosion on hill slope," Geomorphology, vol. 32, no. 3-4, pp. 385-415, 2000.

[5] J. Collinet and C. Valentin, "Evaluation of erosion factors in Western Africa using rainfall simulation," in Proceedings of Challenges in African Hydrology and Water Resources Symposium, vol. 144, pp. 451-461, Harare, Zimbabwe, June 1984.

[6] V. Chaplot and Y. Le Bissonnais, "Field measurements of interrill erosion under different slopes and plot sizes," Earth Surface Processes and Landforms, vol. 25, no. 2, pp. 145-153, 2000.

[7] Y. Hamed, J. P. Albergel, Y. Pepin et al., "Comparison between rainfall simulator erosion and observed sedimentation in an erosion-sensitive semiarid catchment," Catena, vol. 50, no. 1, pp. 1-16, 2002.

[8] S. R. Choupoupno, "Développement international, Communauté urbaine de Douala: Plan directeur d'urbanisation horizon 2025, Présentation de la Communauté. Communauté Cible:Douala 3ème, Choix du site : quartier nyalla," Mémoire de fin d'étude de DIPET II, Ecole Normale Supérieur de l'Enseignement Technique de l'Université de Douala, vol. 13, p. 85, 2012.

[9] E. F. Mbiakouo, E. Njeugna, D. Techeukam, and D. Fokwa, "Hydrodynamic characterisation of soil in the Estuaries coast of Cameroon-Gulf of Guinea, 2014 coast of Cameroon-Gulf of Guinea," Journal of engineering and Applied Sciences, vol. 9, no. 4, pp. 61-68, 2014.

[10] K. Warlouzel, Caractérisation et comportement des Géotextiles pour la lutte contre l'érosion pluviale des sols: étude des mécanismes de protection et de compatibilité avec la végétation [Ph.D. Thesis], Université Joseph Fourier Grenoble I, 210 pages, 1999.

[11] A. Kemajou, De l'initiation à la maitrise de la climatisation, et $d u$ conditionnement de l'air, p. 317, d'Alexis Kemajou, Cameroun, France, Editoin Masseu, 2009.

[12] P. Hénensal and F. Duchatel, "Erodimètre à jets mobiles," Bulletin de liaison des laboratoires des ponts et chaussées, vol. 167, pp. 47-52, 1990.

[13] E. L. Garouani, A. Chen, H. Lewis, A. Tribak, and M. Abahrour, Apport de la Télédétection et du SIG pour le suivi spatio-temporel de l'occupation du sol et de l'érosion nette dans le bassin de l'Oued Tlata (Maroc), pp. 6-9, Acte des JSIRAUF, Hanoi, Vietnam, 2007.

[14] F. R. Troeh, J. A. Hobbs, and R. L. Donahue, Soil and Water Conservation: Productivity and Environmental Protection, Prentice-Hall, Upper Saddle River, NJ, USA, 3rd edition, 1999.

[15] K. N. Brooks, P. F. Folliot, and J. A. Magner, Hydrology and the Management of Watersheds, Wiley-Blackwell, Ames, IA, USA, 4th edition, 2013.

[16] Intergovernmental Panel on Climate Change, Climate Change 2014: Synthesis Report Contribution of Working Groups I, II, and III to the Fifth Assessment Report of the Intergovernmental
Panel on Climate Change, R. K. Pachauri and L. A. Meyer, Eds., Core Writing Team, IPCC, Geneva, Switzerland, 2015.

[17] J. Cornelissen, S. Lavorel, E. Garnier et al., "Empirical models for predicting the erosion-reducing effects of plant roots during concentrated flow erosion," Geomorphology, vol. 118, pp. 425-432, 2010.

[18] R. Evans, "Land use and accelerated erosion soil erosion by water in a small catchment on the South Downs," Landscapes through the Lens, D. C. Cowley, R. A. Standring, and M. J. Abicht, Eds., pp. 129-142, Occasional Publication of the Aerial Archaeology Research Group No 2 Oxbow Books, Oxford, West Sussex, England, 2010.

[19] F. A. L. Pacheco, S. G. P. Varandas, L. F. Sanches Fernandes, and R. F. Valle Jr., "Soil losses in rural watersheds with environmental land use conflicts," Science of the Total Environment, vol. 485-486, pp. 110-120, 2014.

[20] C. Centeri, R. Pataki, and A. Barczi, "Soil erosion, soil loss tolerance and sustainability in Hungary," in Proceedings of $3 r d$ International Conference on Land Degradation and Meeting of the IUSS Sub commission C-Soil and Water Conservation, Rio de Janeiro, Brazil, September 2001.

[21] R. Evans, "An alternative way to assess water erosion of cultivated land-field-based assessments: and analysis of some results," Applied Geography, vol. 22, pp. 187-208, 2002.

[22] R. Evans, "Monitoring water erosion in lowland England and Wales-A personal view of its history and outcomes," Catena, vol. 64, no. 2-3, pp. 142-161, 2005.

[23] R. F. Valle Jr., S. G. P. Varandas, L. F. Sanches Fernandes, and F. A. L. Pacheco, "Environmental land use conflicts: a threat to soil conservation," Land Use Policy, vol. 41, pp. 172-185, 2014.

[24] F. B. Pierson, C. J. Williams, P. R. Kormos et al., "Hydrologic vulnerability of sage brush steppe following piny on and juniper encroachment," Rangeland Ecology and Management, vol. 63, no. 6, pp. 614-629, 2010.

[25] F. B. Pierson, C. J. Williams, S. P. Hardegree, P. E. Clark, P. R. Kormos, and O. Z. Al-Hamdan, "Hydrologic and erosion responses of sage brush steppe following juniper encroachment, wildfire, and tree cutting," Rangeland Ecology \& Management, vol. 66, no. 3, pp. 274-289, 2013.

[26] C. J. Williams, F. B. Pierson, O. Z. Al-Hamdan, P. R. Kormos, S. P. Hardegree, and P. E. Clark, "Can wildfire serve asaneco hydrologic thres hold-reversal Mechanism on juniperencroached shrublands," Ecohydrology, vol. 7, no. 2, pp. 453-477, 2014.

[27] C. J. Williams, F. B. Pierson, P. R. Robichaud, O. Z. AlHamdan, J. Boll, and E. K. Strand, "Structural and functional connectivity as a drive rofhill slope erosion Following disturbance," International Journal of Wild land Fire, vol. 25, no. 3, pp. 306-321, 2016.

[28] J. E. Mitchell and S. R. Roundtable, Criteria and Indicators of Sustainable Rangeland Management, University of Wyoming, Cooperative Extension Service, Laramie, WY, USA, 2010.

[29] K. E. Spaeth, F. B. Pierson, M. A. Weltz, and W. H. Blackburn, "Evaluation of USLE and RUSLE estimated soil loss on Range land," Journal of Range Management, vol. 56, no. 3, pp. 234-246, 2003.

[30] L. Mabit, M. R. Laverdière, and C. Bernard, "L'érosion hydrique: méthodes et études de cas dans le Nord de la France," Cahiers Agricultures, vol. 11, pp. 9-10, 2002.

[31] W. H. Wischmeier and D. D. Smith, "A universal soil-loss esti- mating equation to guide conservation farm planning," Soil Science, vol. 1, pp. 418-425, 1960. 
[32] Y. Tardy, Le cycle de l'eau: climats, paléoclimats et géochimie globale, p. 338, Masson, Paris, France, 1986.

[33] Y. Le Bissonnais, A. Bruand, and M. Jamagne, "Laboratory experimental study of soil crusting: relation between aggregate breakdown mechanisms and crust structure," Catena, vol. 16, no. 4-5, pp. 377-392, 1989.

[34] A. Markhi, N. E. Laftouhi, A. Soulaimani, and F. Fniguire, "Quantification et évaluation de l'érosion hydrique en utilisant le modèle RUSLE et déposition intégrés dans un SIG, Application dans le bassin N'fis dans le haut atlas de Marrakech (Maroc)," European Scientific Journal, vol. 11, pp. 340-356, 2015.

[35] M. Kouli, P. Soupios, and F. Vallianatos, "Soil erosion prediction using the Revised Universal Soil Loss Equation (RUSLE) in a GIS framework, (RUSLE) in a GIS framework, Chania, North-western Crete, Greece," Environmental Geology, vol. 57, no. 3, p. 483e497, 2009.

[36] Y. Farhan, D. Zregat, and I. Farhan, "Spatial estimation of soil erosion risk using RUSLE approach, RS, and GIS techniques, techniques: a case study of Kufranja Watershed, Northern Jordan," Journal of Water Resource and Protection, vol. 5, no. 12 , pp. 1247-1261, 2013

[37] B. Bep, P. Zahonero, Z. Boli, and E. Roose, "Evaluation des états de surface et influence sur le ruissellement et l'érosion des sols ferrugineux tropicaux sableux du Nord Cameroun soumis à divers techniques culturales," Réseau Erosion du centre ORSTOM, vol. 1, pp. 59-77, 1995.

[38] Y. M. Mohamed, R. Bouabid, A. El Hmaidi, A. Essahlaoui, and M. Abassi, "Modélisation de l'érosion hydrique via les SIG et l'équation universelle des pertes en sol au niveau du bassin versant de l'Oum Er-Rbia," International Journal of Engineering and Science, vol. 3, pp. 83-91, 2014.

[39] A. Adam Kertesz, "Érosion des versants et transport solides à l'exutoire d'un bassin versant a Hongrie," Reseau Erosion Bullettin, vol. 20, pp. 104-111, 2000.

[40] A. Raissouni, L. Khali Issa, R. Moussadek, R. Mrabet, and A. EL Arrim, "Erosion hydrique et transferts des matières vers les zones côtières méditerranéennes. Cas du bassin de l'oued Khmiss (Rif nord occidental. Maroc)," in Conférence Méditerranéenne Côtière et Maritime, Tangier, Morocco, November 2011, http://www.paralia.fr.

[41] R. C. Palmer and R. P. Smith, "Soil structural degradation in SW England and its impact on surface-water runoff generation, runoff generation," Soil Use and Management, vol. 29, no. 4, pp. 567-575, 2013.

[42] V. Prasuhn, "Soil erosion in the Swiss midlands: results of a ten year field survey," Geomorphology, vol. 126, no. 1-2, pp. 32-41, 2011.

[43] Y. Liu, "Landscape connectivity in soil erosion research: concepts, implication, quantification," Geographical Research, vol. 1, pp. 195-202, 2016.

[44] D. R. Montgomery, M. Y. F. Huang, and A. Y. L. Huang, "Regional soil erosion in response to land use and increased typhoon frequency and intensity, Taiwan," Quaternary Research, vol. 81, no. 1, pp. 15-20, 2014.

[45] E. Nadeu, A. A. Berhe, J. de Vente, and C. Boix-Fayos, "Erosion, deposition and replacement of soil organic carbon in mediterranean catchments: a geomorphological, geomorphological, isotopic and land use change approach," Bio Geosciences, vol. 9, no. 3, pp. 1099-1111, 2012.

[46] X. Y. Niu, W. Yan-Hua, Y. Hao et al., "Effect of land use on soil erosion and nutrients in Dianchi Lake Watershed, China," Pedosphere, vol. 25, no. 1, pp. 103-111, 2015. 

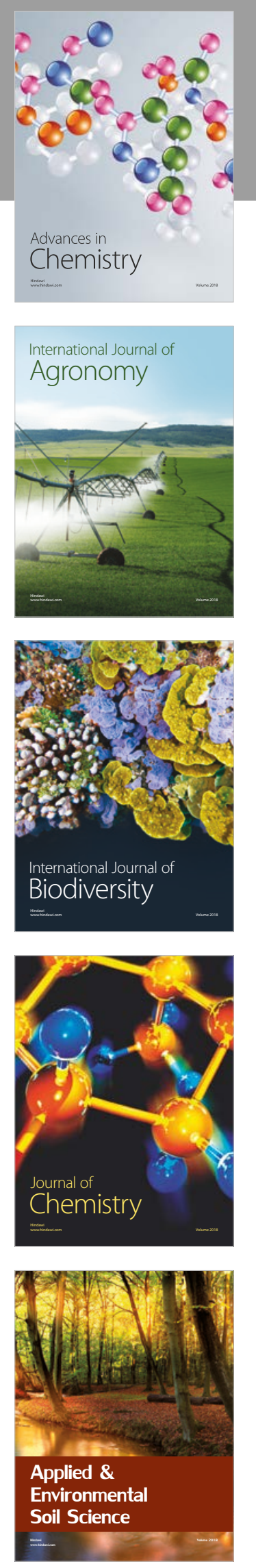

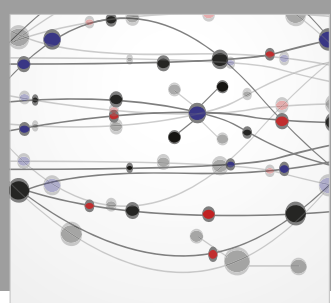

The Scientific World Journal

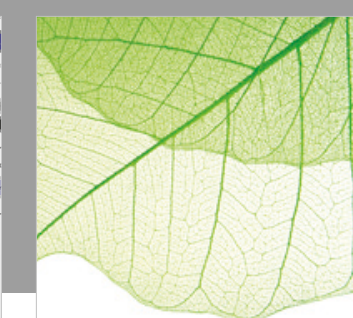

Journal of Botany

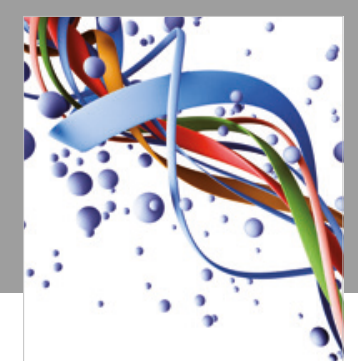

Scientifica

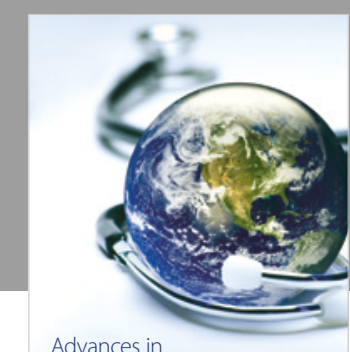

Public Health

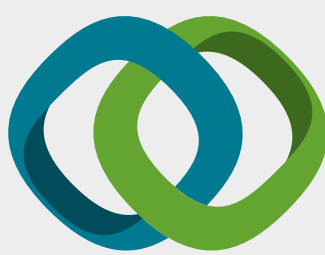

Hindawi

Submit your manuscripts at

www.hindawi.com
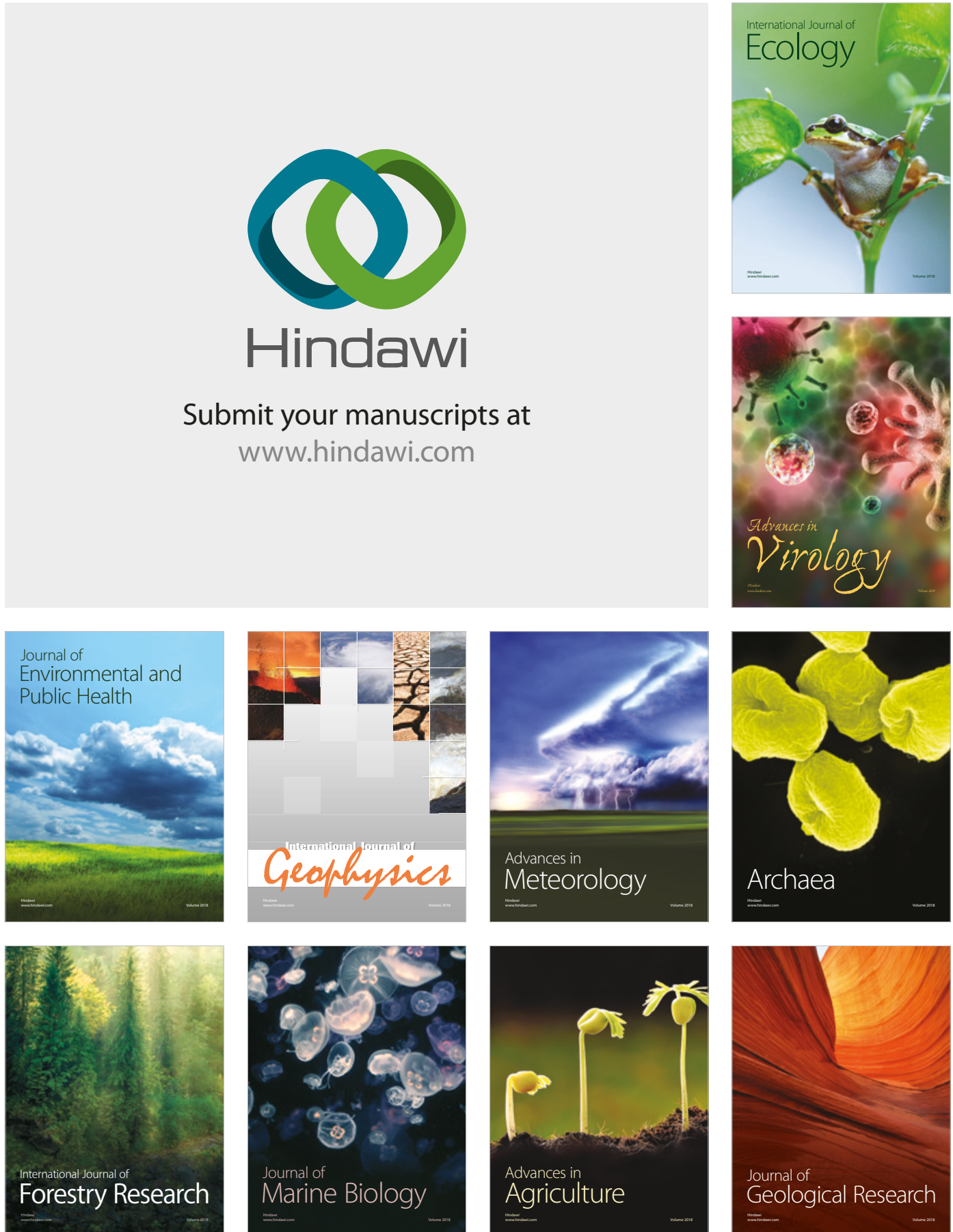

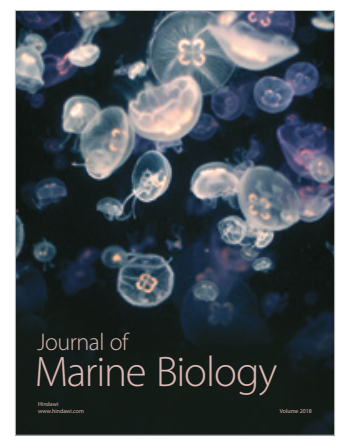

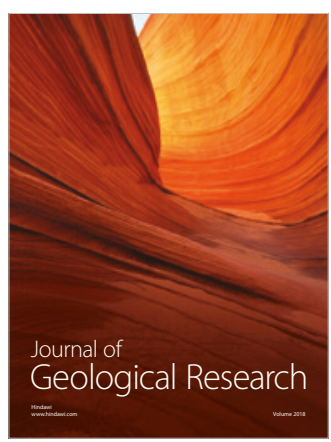

